\title{
Insecticide resistance in disease vectors from Mayotte: an opportunity for integrated vector management
}

Nicolas Pocquet ${ }^{1 *}$, Frédéric Darriet ${ }^{1}$, Betty Zumbo ${ }^{2}$, Pascal Milesi $^{3}$, Julien Thiria ${ }^{2,3,4}$, Vincent Bernard ${ }^{1}$, Céline Toty ${ }^{1,2}$, Pierrick Labbé $e^{3}$ and Fabrice Chandre ${ }^{1}$

\begin{abstract}
Background: Mayotte, a small island in the Indian Ocean, has been affected for many years by vector-borne diseases. Malaria, Bancroftian filariasis, dengue, chikungunya and Rift Valley fever have circulated or still circulate on the island. They are all transmitted by Culicidae mosquitoes. To limit the impact of these diseases on human health, vector control has been implemented for more than 60 years on Mayotte. In this study, we assessed the resistance levels of four major vector species (Anopheles gambiae, Culex pipiens quinquefasciatus, Aedes aegypti and Aedes albopictus) to two types of insecticides: i) the locally currently-used insecticides (organophosphates, pyrethroids) and ii) alternative molecules that are promising for vector control and come from different insecticide families (bacterial toxins or insect growth regulators). When some resistance was found to one of these insecticides, we characterized the mechanisms involved.
\end{abstract}

Methods: Larval and adult bioassays were used to evaluate the level of resistance. When resistance was found, we tested for the presence of metabolic resistance through detoxifying enzyme activity assays, or for target-site mutations through molecular identification of known resistance alleles.

Results: Resistance to currently-used insecticides varied greatly between the four vector species. While no resistance to any insecticides was found in the two Aedes species, bioassays confirmed multiple resistance in $C X$. p. quinquefasciatus (temephos: 20 fold and deltamethrin: only 10\% mortality after 24 hours). In An. gambiae, resistance was scarce: only a moderate resistance to temephos was found $(\sim 5$ fold). This resistance appears to be due only to carboxyl-esterase overexpression and not to target modification. Finally, and comfortingly, none of the four species showed resistance to any of the new insecticides.

Conclusions: The low resistance observed in Mayotte's main disease vectors is particularly interesting, because it leaves a range of tools useable by vector control services. Together with the relative isolation of the island (thus limited immigration of mosquitoes), it provides us with a unique place to implement an integrated vector management plan, including all the good practices learned from previous experiences.

Keywords: Insecticide resistance, Mosquito control, Resistance management, Integrated vector management

\footnotetext{
* Correspondence: nicolas.pocquet@ird.fr

'Institut de Recherche pour le Développement, Unité Mixte de Recherche MIVEGEC (IRD 224-CNRS 5290-UM1-UM2), 911, avenue Agropolis, BP 64501 34394 Montpellier cedex 5, France

Full list of author information is available at the end of the article
} 


\section{Background}

Mayotte is a French island located in the Indian Ocean, in the Comoros archipelago. For many years, this island has been heavily affected by vector-borne diseases. Historically, the two diseases that mainly plagued the island were Bancroftian filariasis, mostly transmitted by Culex pipiens quinquefasciatus [1-4], and malaria, transmitted by several anopheline species, including Anopheles gambiae s.s. [5,6]. Today, malaria is still present in Mayotte, although the number of cases has significantly decreased during the last two years [7]. Moreover, while the disease was considered eliminated from the island, some cases of Bancroftian filariasis were recently recorded [8].

In addition to these endemic diseases, a major dengue fever outbreak in 1943 [9] and a chikungunya outbreak in 2005 and 2006 have also affected Mayotte [10]. Both are due to arboviruses transmitted by Aedes species. However, while dengue was principally transmitted by Aedes aegypti, chikungunya main vector was Ae. albopictus [11]. This last species, observed for the first time on the island in 2001 [12], has since almost completely replaced Ae. aegypti [13], and certainly played the main role in the recently recorded cases of dengue and chikungunya [14]. Finally, new arboviruses recently started to circulate on the island, including the Rift Valley Fever virus [15].

To limit the impact of these diseases on people from Mayotte, many vector control programs have been implemented since the early 50s [16]. Most of the efforts were intended to control $C x . p$. quinquefasciatus and An. gambiae populations, to prevent filariasis and malaria. They relied almost entirely on the use of chemical insecticides (from the organochlorines (OC), organophosphates (OP) and pyrethroids (PYR) families), through extensive applications on larval breeding sites, indoor residual spraying treatments (IRS) $[3,5,9,16-18]$ and, more recently, long-lasting insecticide treated nets (LLIN). These vector control campaigns have had good results and greatly limited the impact of lymphatic filariasis and malaria in Mayotte [4,6]. Today however, several constraints could impede vector control. The first constraint is administrative, with a significant reduction of the number of insecticides available for vector control due to new European ${ }^{\mathrm{a}}$ regulations [19]. All pesticide molecules had indeed to be re-examined in 2007 for marketing authorization, through a costly application filed by the producers; some unprofitable yet efficient molecules were not supported. There are also technical difficulties, due to the increasing role of Ae. albopictus as a major vector of arboviruses in Mayotte. Due to their preferences for confined larval breeding sites (natural, like tree holes, or artificial, like used tires) and their eggs resistant to desiccation [20,21], Ae albopictus is particularly difficult to reach through conventional sprays of insecticides. The third type of constraints is ecological: Mayotte is a small island with a specific ecosystem encompassing many endemic species, and as such must be protected from anthropic pollutions. The effects of insecticide treatments on non-target fauna and their potential accumulation in the food chain need to be taken into account and limited. Finally, the last and most important challenge come from evolutionary process: the long-term use of insecticides is known to select for resistance of the target insects, with the possible effect of rendering the available molecules ineffective for control [22].

However, in Mayotte, almost nothing was known on the resistance status of the various mosquito vectors, until a recent study on $C x$. $p$. quinquefasciatus [23]. This study showed that many resistance mechanisms were present in this species, so that the lack of data for the other vectors became a major concern. In view of the history of insecticide treatments in the island, many resistance mechanisms could have been selected in the other species as well, and could prevent efficient vector control measures. There are indeed a large number of insecticide resistance mechanisms in mosquitoes, mainly through metabolic resistances or insecticide target modifications (review in: [24-26]). The usual way of overcoming resistance is to change the molecule used to restore efficient vector control. However, the number of new molecules available is continuously shrinking [27], and cross-resistance (i.e. the fact that one resistance mechanism is able to confer resistance to other molecule families) could lead to an additional reduction of alternatives [28].

All these constraints have to be considered to implement a rational and sustainable vector control plan. In this type of plan, it is clearly important to monitor the resistance levels to currently-used insecticides and to assay the few valuable and authorized molecules that could replace them in case of insecticide resistance development in the targeted vectors.

In this study, the four main mosquito vectors of the island (Cx. p. quinquefasciatus, An. gambiae, Ae. aegypti and Ae. albopictus) were thus investigated to determine their levels of resistance to the insecticides currently used in Mayotte: temephos (OP), Bti (bacterial toxins (BacT) extracted from Bacillus thuringiensis var israelensis), and deltamethrin (PYR). When resistance was found, the mechanisms involved were characterized through biochemical and molecular analyses. In addition, resistance to four candidate insecticides for vector control in Mayotte was also assayed: spinosad, an insecticide of bacterial origin (Spinosyns), and three insect growth regulators or IGRs, diflubenzuron, pyriproxyfen and methopren. The results are discussed in the light of the vector control strategies usable to prevent emergence and spread of resistance in the island vectors. 


\section{Methods}

\section{Mosquito samples and strains}

Five laboratory strains were used in this study: An. gambiae KIS strain [29], Cx. p. quinquefasciatus SLAB strain [30], Ae. aegypti BORA strain [31] and Ae. albopictus PLP strain [32] were used as susceptible reference strains; the $A n$. gambiae AcerKIS strain [33], homozygous for the G119S mutation of acetylcholinesterase [34], was used as the OPresistant reference strain in this species.

Field larvae of An. gambiae, Cx. p. quinquefasciatus, Ae. aegypti and Ae. albopictus were collected in Mayotte between 2010 and 2011. Natural populations (Figure 1) were sampled from a garbage dump in Dzoumogné for An. gambiae (DZOU), an open sewer in Tsoundzou for Cx. p. quinquefasciatus (TZ1), several peri-domestic breeding sites in Petite Terre for Ae. aegypti (PT) and a stock of used tires in Kaweni for Ae. albopictus (KWI). The larvae of An. gambiae and Cx. p. quinquefasciatus were collected at early instars $\left(1^{\text {st }}\right.$ or $\left.2^{\text {nd }}\right)$, reared in the laboratory to $3^{\text {rd }}$ instar, and used for bioassays. The larvae of Ae. aegypti and Ae. albopictus were reared to adulthood in the laboratory. Mono-specific colonies of

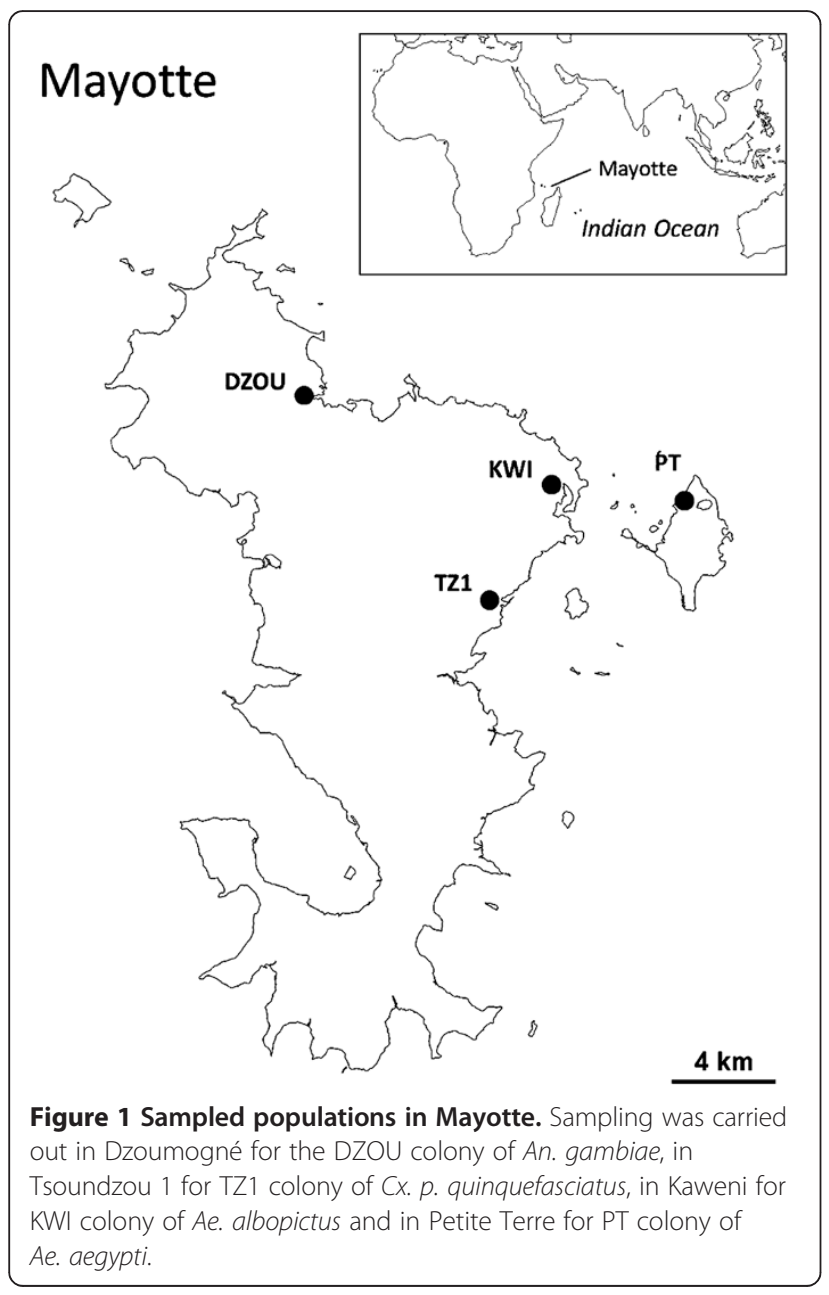

Ae. aegypti and Ae. albopictus were established, and females were blood-fed to obtain F1 offsprings, which were used for bioassays $\left(3^{\text {rd }}\right.$-instar larvae). In $C x . p$. quinquefasciatus, Ae. aegypti and Ae. albopictus samples, some of the field larvae were kept, reared, and the adults were bred in the laboratory to establish TZ1, PT and KWI colonies. These colonies were used for IGR bioassays. Due to technical difficulties for establishing an $A n$. gambiae colony from field individuals, IGR bioassays were directly performed on field-collected larvae.

Finally, to overcome the difficulties to establishing an An. gambiae colony while remaining close to the original field population (as for the other species), the DZOU temephos resistance gene(s) were introgressed into the genome of the KIS strain, leading to the DZKIS strain. DZOU males were crossed with unmated females of the KIS strain and their progeny reared in the laboratory. Third-instar larvae were selected with temephos at a dose killing $80 \%$ of the individuals. Male survivors were backcrossed on females of the KIS strain and selected again. The following generations were then left to cross among themselves, $3^{\text {rd }}$-instar larvae being selected with temephos at each generation, until the resistance level had stopped increasing (10 generations). This protocol provided the DZKIS strain, containing mainly DZOU genome (the field population colony), and just enough KIS genome to be lab-adapted. It also resulted in a strain more homogeneous in terms of resistance.

\section{Bioassays}

Larval and adult bioassays were performed following WHO protocols [35,36]. Larval bioassays were carried out using ethanol solutions of the following active ingredients, temephos (OP), chlorpyrifos (OP), malathion (OP), propoxur (carbamate, or $\mathrm{CM}$ ), spinosad (Spinosyns), diflubenzuron (IGR), pyriproxyfen (IGR) and methopren (IGR) (spinosad from Dow Agro Sciences, Indianapolis, USA; other products from Sigma-Aldrich, Germany), and using water solutions of Bti (BacT) formulation (Vectobac 12AS, 1200 ITU/ mg). Larval bioassays were conducted on sets of 25 early $3^{\text {rd }}$-instar larvae placed in a cup with $99 \mathrm{ml}$ of water. One $\mathrm{ml}$ of the tested insecticide solution was then added in each cup. Assays of four to nine doses in a minimum of two cups per dose were performed for each insecticide. Two replicates were performed for temephos, spinosad and Bti, and one or two replicates were performed for chlorpyrifos, malathion, propoxur and IGR insecticides (it results in 250 to 1500 mosquitoes assayed for each insecticide). In temephos, spinosad, chlorpyrifos, malathion, propoxur and Bti assays, larval mortality was recorded after 24 hours of insecticide exposure. For IGR assays, the total number of larvae in each cup was recorded after 24 hours and the number of emerging adults was recorded daily. Emergence Inhibition (EI) is calculated for each dose by subtracting the 
number of emerged adults to the total number of larvae at the beginning of the test. Note that in such IGR tests, regular feeding of larvae is required, due to their duration (over 10 days). For Aedes and Culex larvae, 3 to $5 \mathrm{mg}$ per cup of a mixture of dog and fish foods were added every day. For Anopheles larvae, 0.5 to $1.5 \mathrm{mg}$ per cup of fish food were added on the surface. The quantity of food was decreased at the appearance of the first pupae, as some larvae were still feeding.

Adult bioassays were carried out using WHO test tubes. This device allows exposing sets of 25 adult females (2-5 days old) to a filter paper impregnated with deltamethrin at a dose of $0.05 \%$ (products from SigmaAldrich, Germany). This diagnostic dose kills 100\% of individuals in a susceptible population [37]. Four sets of 25 females were exposed for 60 minutes to deltamethrin to evaluate its knockdown effect (KD) on each colony or strain. Mortality was recorded after 24 hours. Two replicates per colony/strain were performed.

The analyses of dose-mortality responses were performed using the $\mathrm{R}$ software [38]. The $\mathrm{R}$ script BioRssay was used; it is freely available on the website of the Institut des Sciences de l'Evolution de Montpellier [39]. This script computes the doses of insecticide killing 50\% and $95 \%$ of the tested colony or strain (Lethal Concentration 50 and 95 , or $\mathrm{LC}_{50}$ and $\mathrm{LC}_{95}$ ) and the associated confidence intervals, using a script modified from Johnson et al. [40], which allows taking into account the heterogeneity of the data [41]. Mortality in controls is taken into account using the correction from the Abott's formula [42]. A generalized linear model (GLM) with a binomial error and a probit link is then fitted to the data where the probit mortality is a function of the logarithm of the dose of insecticide for each colony/strain. The script also computes the slope and intercept of the regression for each colony/strain (and their standard errors), and tests for the linearity of the dose-mortality response $\left(\chi^{2}\right.$ test). Finally, it allows the comparison of two or more strains or colonies and calculates the resistance ratios, i.e. $\mathrm{RR}_{50}$ or $\mathrm{RR}_{95}\left(=\mathrm{LC}_{50}\right.$ or $\mathrm{LC}_{95}$ of tested colony/LC $\mathrm{L}_{50}$ or $\mathrm{LC}_{95}$ of the reference strain, resp.) and their $95 \%$ confidence intervals. A RR in which the confidence interval does not include 1 was considered as statistically significant, so that the tested colony was significantly more resistant than the reference. Note, however, that even slight differences between colonies/ strains can be statistically significant, due to the high number of mosquitoes tested. However, even a statistically significant $R R<3$ is usually considered of limited biological significance (such RR can be obtained when comparing susceptible strains, e.g. [43]), and we applied this criterion here. The script then builds custom graphs and a summary text file with the different parameters and tests is provided.
The same script was used to calculate the Emergence Inhibition Concentrations for IGR insecticides $\left(\mathrm{EIC}_{50}\right.$ and $\left.\mathrm{EIC}_{95}\right)$ and the KnockDown Times for deltamethrin $\left(\mathrm{KDT}_{50}\right.$ and $\left.\mathrm{KDT}_{95}\right)$.

\section{Metabolic resistance}

Biochemical tests were performed on single 2-5 daysold females from the An. gambiae DZOU colony to evaluate the activity of the main families of detoxifying enzymes. Protein amount was quantified in microplates using the method of Bradford [44], the quantity or activity of the different detoxifying enzymes were expressed per mg of protein present in the homogenate or quantity of molecules metabolized per minute, respectively. Cytochrome P450 monooxygenases (named mixed function oxidases or MFO) were quantified indirectly by the peroxidase activity of the heme group with tetramethylbenzidine (note that all hemoproteins are thus quantified, not only MFO; [45]). Carboxyl-esterases (COE) were quantified indirectly by their ability to hydrolyze $\alpha$ naphthyl and $\beta$-naphthyl acetate [46].

Statistical comparisons of detoxifying enzyme activities present in the $A n$. gambiae susceptible strain KIS and the DZOU colony were computed using Mann-Whitney tests with the Statistica software [47].

\section{Analyses of target-site modifications}

Total DNA of single mosquitoes of the An. gambiae DZOU colony was extracted using the CTAB protocol [48]. The G119S mutation, carried by the ace- $1^{R}$ allele of the acetylcholinesterase-1 gene (AChE1), was investigated using the PCR-RFLP test described by Weill et al. [49]. Two substitutions in the $k d r$ gene are known to cause resistance to PYR in An. gambiae: L1014F and L1014S, respectively most often encountered in West Africa and East Africa. They were investigated using the multiplex-PCR described in Martinez-Torres et al. [50] and Ranson et al. [51], respectively. We thereafter called these two alleles $k d r^{R}$, indifferently. Only the L1014F mutation was found in Culex quinquefasciatus from Mayotte, where it was investigated in our precedent study [23], using the multiplex-PCR described in Martinez-Torres et al. [52]. The resistance allele was called $k d r^{R}$ thereafter.

\section{Results and discussion}

\section{No resistance observed in Ae. aegypti and Ae. albopictus}

Larval bioassays revealed that colonies from field populations of Ae. aegypti and Ae. albopictus (PT and KWI, respectively) did not show biologically significant resistance to any of the tested larvicides (RR between 0.3 and 1.6, Figure 2 and Additional file 1). Similarly, adult bioassays to deltamethrin showed a complete susceptibility of these two species (over 97\% mortality 24 hours after 


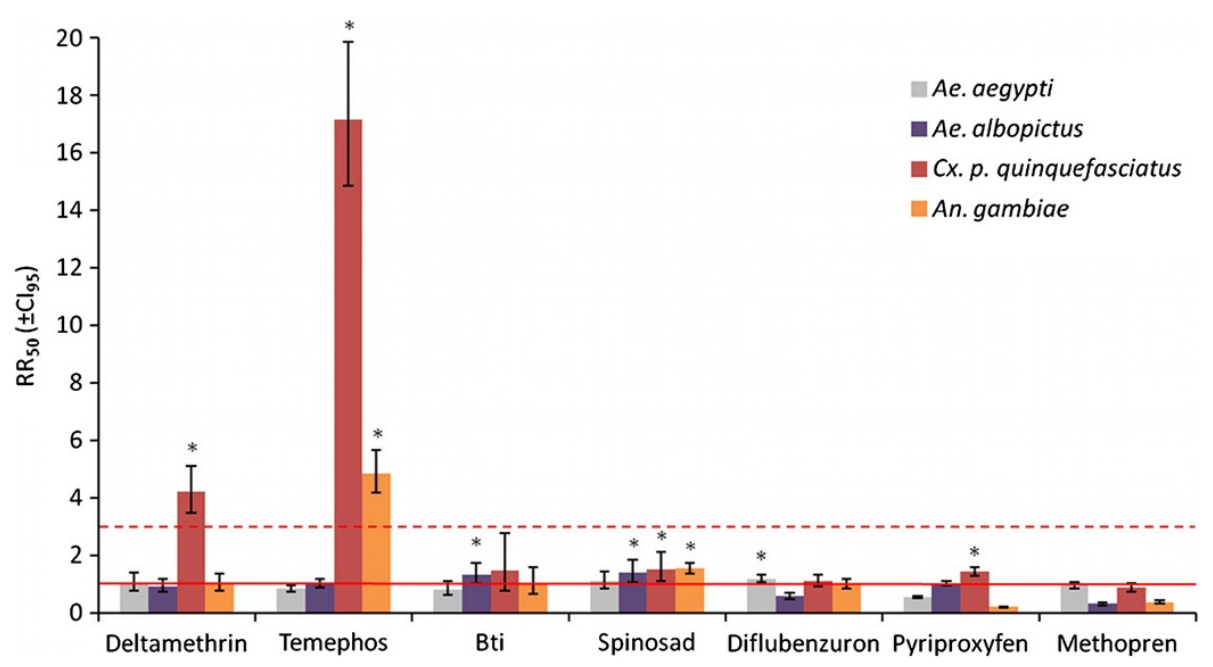

Figure 2 Insecticide resistance in vector mosquitoes from Mayotte. The resistance ratios ( $R R_{50}$, i.e. the ratios of $L C_{50}$ of the tested colonies over the $L C_{50}$ of the susceptible reference strain), of colonies from field populations of Ae. aegypti (gray), Ae. albopictus (purple) CX.p. quinquefasciatus (red) and An. gambiae (orange) to different tested insecticides are presented. The error bars represent the confidence interval of $R R$ at $95 \%$. The solid red line represents $R R=1$ (i.e. a $L C_{50}$ equal to that of the susceptible reference) and the dotted red line represents $R R=3$ (resistance is considered of biological significance when above). RR significantly higher than 1 (i.e. when $\mathrm{Cl}_{95}$ does not include 1) are indicated by a star.

exposure) and no increase of knockdown times was observed as compared to the susceptible reference strains (RR between 0.9 and 1, Figure 2 and Additional file 2).

The susceptibility of these two Aedes species to IGRs, Spinosad and Bti is not surprising because these insecticides have never been used on the island before 2011 ([16]; Belon, personal communication). Since 2011, Bti has been used by the vector control service of Mayotte as a larvicide, but not against Aedes species.

In contrast, temephos (larvicide) was used in Mayotte from 1973 to 2012 and deltamethrin (adulticide) has been used since 1984 ([16], Belon, personal communication), but no resistance was observed in either $A e$. aegypti or Ae. albopictus. Several factors may explain the absence of resistance to deltamethrin and temephos in these two species. First, before the 2005-2006 chikungunya outbreak [10], these species were not targeted by vector control treatments. Since the epidemic, control against these two vectors is essentially based on social mobilization and physical destruction of breeding sites. Only few insecticide treatments have therefore been carried out specifically against Aedes species in Mayotte. Secondly, their main breeding sites are peri-domestic containers used for water storage and small water collections in peri-urban areas (coconut, dead leaves, used tires, etc. [20,21]). These soil-less breeding sites are little affected by environmental xenobiotic contamination (insecticides or pollutants) and difficult to reach by the vector-control teams. Thirdly, deltamethrin is used in Mayotte either in Indoor Residual Spraying (IRS), or on Long Lasting Insecticide-treated Nets (LLIN). These two modes of treatment target adult female mosquitoes, but only indoors. Ae. albopictus and Ae. aegypti being diurnal and exophagous species [53,54], they are therefore not likely to be affected by LLINs, which protect people when sleeping. In addition, Ae. albopictus is an exophilic species [54], and although Ae. aegypti females can rest indoors, they do so preferentially on untreated surfaces $[55,56]$, so that IRSs have little effect on these species. Overall, Ae. albopictus and Ae. aegypti are therefore likely to be subject to weak selection, which probably explains their complete susceptibility. This situation is radically different from that observed for some other French islands. For example, on the Martinique island, Ae. aegypti is the main target of vector control interventions, and this species presents strong levels of PYR resistance in this place [57]. A final remark concerning insensitive acetylcholinesterase target of OP and CM: it has been shown that, in these two Aedes species, the G119S mutation of this enzyme is highly unlikely, due to molecular constraints [58]. It was thus not surprising that this particular type of resistance was lacking, and it is unlikely to evolve in the future.

\section{High levels of resistance in $C x . p$. quinquefasciatus}

The results for $C x . p$. quinquefasciatus are in sharp contrast to those of the two Aedes species. Larval and adult bioassays on TZ1 colony indeed revealed strong resistance respectively to temephos $\left(R_{50}=17.2, R_{95}=18.9\right.$; Figure 2 and Additional file 1) and to deltamethrin (10\% of mortality after 24 hours and a strong decrease of knockdown effect: $\mathrm{RR}_{50}=4.2, \mathrm{RR}_{95}=4.9$; Figure 2 and 
Additional file 2). However, no biologically significant resistance to any of the other tested insecticides has been identified in this colony $\left(R_{50}\right.$ between 0.9 and 1.5 , Figure 2 and Additional file 1), even if TZ1 colony showed a low resistance at $\mathrm{LC}_{95}$ to juvenile hormone analogs (pyriproxyfen and methopren, $\mathrm{RR}_{95}=4.9$ and 4.1 respectively).

The resistance mechanisms of $C x$. p. quinquefasciatus in Mayotte have been studied in depth recently (see [23]). Two mechanisms of resistance to OPs were found on the island. The first was an overexpression of esterases, encoded by the Ester ${ }^{2}$ allele, and the second was a modification of the AChE1, due to the G119S mutation of the gene $a c e-1$. Both were found at relatively high frequencies (0.59 for Ester ${ }^{2}$ and 0.39 for ace- $1^{R}$; [23]). Similarly, the $k d r^{R}$ allele, coding for a modification of the sodium channels allowing resistance to PYRs was found almost fixed on the entire island $\left(k d r^{R}\right.$ frequency $\left.=0.98\right)$. Biochemical tests and bioassays with synergists did not reveal MFO involvement in PYR resistance [23]. The $k d r^{R}$ allele thus appeared to be the main allele responsible for deltamethrin resistance, although the involvement of other metabolic resistance cannot be excluded. The low resistance to juvenile hormone analogues observed at the high doses could thus be due to the overproduction of esterases in this colony [23], as described in other insect species [59].

$C x . p$. quinquefasciatus is the major vector of the Bancroftian filariasis, which has been plaguing Mayotte for many years $[1,2,4]$. Since the 50 s, intense vector control efforts have been carried out against this species [16]. Many neurotoxic insecticides targeting AChE1 (OPs) and sodium channels (DDT followed by PYRs) have been used to control it $[3,5,16-18]$. These important selective pressures certainly explain the strong resistance to temephos and deltamethrin observed in the TZ1 colony. Such strong resistance to PYRs and OPs is not an isolated case in the Indian Ocean. Indeed, this species has been shown to also harbor major resistance mechanisms to PYR, OP and OC insecticides in Mauritius, Madagascar and La Réunion [23,32]).

The susceptibility of $C x$. p. quinquefasciatus to Bti and spinosad and the low resistance to IGRs are probably related, similar to the Aedes species, in the fact that these insecticides have not been used in the past in Mayotte. They thus provide interesting alternatives to circumvent the high resistance to the insecticides classically used against Culex.

\section{An original temephos resistance mechanism in An. gambiae}

An. gambiae has always been the main target of insecticidebased vector control in Mayotte, as malaria has been endemic on the island for many years $[5,9,16,17,60]$. In the DZOU colony, a significant resistance to temephos $\left(R_{50}=\right.$
4.8, $\mathrm{RR}_{95}=12.9$; Figure 2 and Additional file 1) was observed but there was no biologically significant resistance to any of the other insecticides (RR between 0.2 and 2).

Whereas the absence of resistance is expected for the larvicides that have never been used in the island before 2011 (Bti, spinosad, IGRs), absence of resistance to the adulticide deltamethrin is particularly striking (over 99\% mortality after 24 hours, and full susceptibility to knockdown effect, RR between 1 and 1.1, Figure 2 and Additional file 2). Surprisingly, PCR performed on $A n$. gambiae adult mosquitoes of the DZOU colony did not show either any known $k d r$ resistance mutation, neither the western (L1014F substitution: $\mathrm{N}=31$, all susceptible homozygous) nor the eastern (L1014S substitution: $\mathrm{N}=$ 28 , all susceptible homozygous). Insecticides that target the sodium channel have indeed been used in Mayotte since the early 70s and are still currently used. DDT (OC) was first used in 1973, to be replaced by deltamethrin (PYR) in the early 80s [16]. In several cases, the development of $A n$. gambiae s.s. insecticide resistance has been associated with selection pressures related to the control of agricultural pests $[29,61,62]$, but in Mayotte there are no areas of intense agriculture. One hypothesis to explain the lack of $k d r^{R}$ alleles is thus that the selection pressure coming only from public health is not enough to maintain these alleles at a detectable level in natural populations. Furthermore, Mayotte is a relatively isolated island and a second hypothesis is that no importation of a $k d r^{R}$ resistance allele has yet taken place. The fact that so far no $k d r^{R}$ mutation has been reported in $A n$. gambiae populations from the closest islands, especially in Madagascar [24,63], gives support to this second hypothesis.

As temephos has been used since 1973 in the island $[16,17]$, the resistance to this insecticide observed in the DZOU colony is more expected. To better understand the mechanism(s) involved, the DZOU colony was partly introgressed in the reference susceptible strain KIS and selected at each generation with temephos, thereby creating the DZKIS strain, which carries a mainly DZOU genome but is able to be maintained in the laboratory. The results of this introgression are presented Figure 3. DZKIS temephos resistance was significantly higher than in DZOU sample at $\mathrm{LC}_{50}\left(\mathrm{RR}_{50}=6.9\right.$ and 4.8 , respectively; Additional file 3$)$, but lower at $\mathrm{LC}_{95}\left(\mathrm{RR}_{95}=3.5\right.$ versus 12.9, respectively; Additional file 3 ). This observation was mainly due to an increase of the slope of the dose-mortality regression between DZOU and DZKIS (1.75 and 7.58 respectively), reflecting a greater genetic homogeneity in the selected strain (due to selection at each generation). Tests carried out on DZKIS with other insecticides that target the AChE1 (Additional file 3) did not show biologically significant cross-resistance to chlorpyrifos $\left(\mathrm{OP}, \mathrm{RR}_{50}=1.2\right)$ and to malathion $\left(\mathrm{OP}, \mathrm{RR}_{50}=2.2\right)$. 


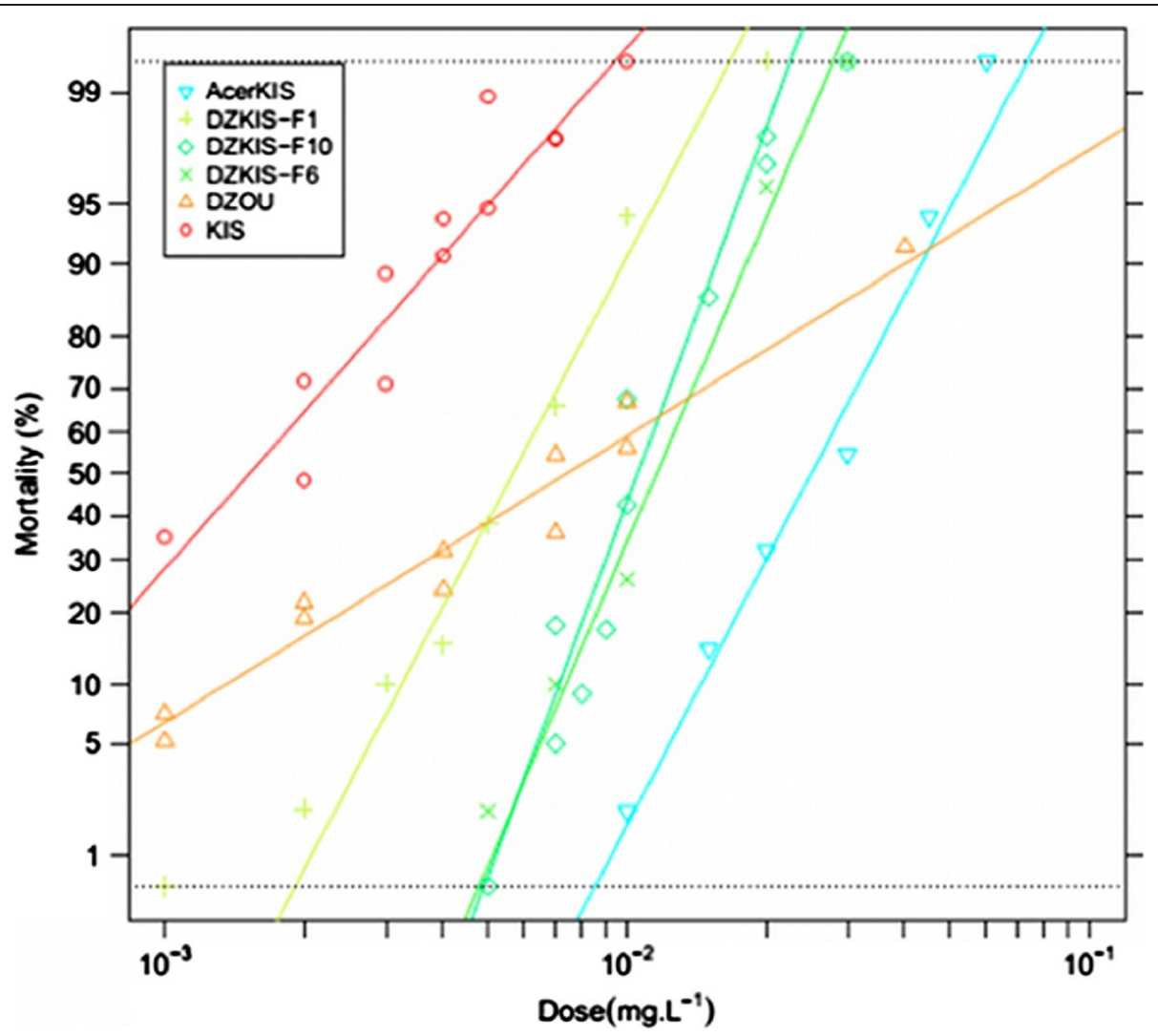

Figure 3 Temephos resistance in the DZKIS strain. The graph shows the evolution of the resistance level to temephos of the DZKIS strain in the $1^{\text {st }}, 6^{\text {th }}$ and $10^{\text {th }}$ (i.e. the last) generations of selection. The dose-mortality of the DZOU original colony and of the KIS and AcerKIS reference strains (respectively susceptible and resistant to OPs through the G119S ace-1 mutation) are also presented.

Moreover, the resistance levels of DZKIS were much lower than those of AcerKIS, the reference $a c e-1^{R}$ strain, for temephos (OP, $\mathrm{RR}_{50}=6.9$ vs 16.4 , respectively), malathion (OP, $\mathrm{RR}_{50}=2.2$ vs 21.5 , respectively) and propoxur $\left(C M, R_{50}=5.6 \mathrm{vs} \approx 10000\right)$. These results thus exclude the presence of insensitive AChE1 associated with G119S mutation. The absence of the ace-1 $1^{R}$ allele was confirmed by PCR performed on adult mosquitoes from the DZOU original sample $(\mathrm{N}=30$, all homozygous for ace-1 susceptible alleles). The activity or quantity of detoxifying enzymes in adult mosquitoes was compared between the DZOU sample and the KIS strain. The activities of $\alpha$ - and $\beta$-esterases were significantly higher in DZOU than in KIS (respectively, 1.19 and 1.47 fold, Mann-Whitney test: $p<0.001$; Figure 4B and C). In contrast, the global quantity of MFO was significantly lower for DZOU than for KIS (0.90 fold, Mann-Whitney test: $\mathrm{p}<0.001$; Figure 4A).

In view of these results, it seems that the temephos resistance observed in An. gambiae from Mayotte is mainly due to COE overexpression or overactivity. Resistance to OPs and to a lesser extent CMs by COEs is commonly encountered in insects [64], particularly in mosquito vectors, such as Culex species $[65,66]$ or Ae. aegypti $[57,67,68]$. This resistance mechanism usually confers a low level of resistance (about 10 fold, [26]), which is consistent with the resistance levels observed in DZOU and DZKIS (temephos and propoxur, 5 to 10 fold, Additional file 3). Although OP and $\mathrm{CM}$ resistance due to COE has already been reported in An. gambiae, it has so far always been found associated to the insensitive AChE1 $[69,70]$, so that the situation in Mayotte is unique.

The DZOU colony breeding-site was a garbage dump, where a large variety of pollutants are present. This is a quite unexpected biotope for this species that usually prefers clean water collection. Such an environment, polluted by xenobiotics and organic matter, could have promoted the selection for an increase of COE expression, as it has been observed for other resistance mechanisms [71,72]. However, An. gambiae was also directly targeted by significant OP-based control in Mayotte $[5,16]$. The selective pressure generated by these treatments did not lead to the selection of the G119S ace-1 mutation locally, and/or the allele was not imported, probably thanks to the island isolation (while it is extensively present in West Africa for example [33]). The contrast with $C x . p$. quinquefasciatus is striking and will require more studies to be fully understood. 

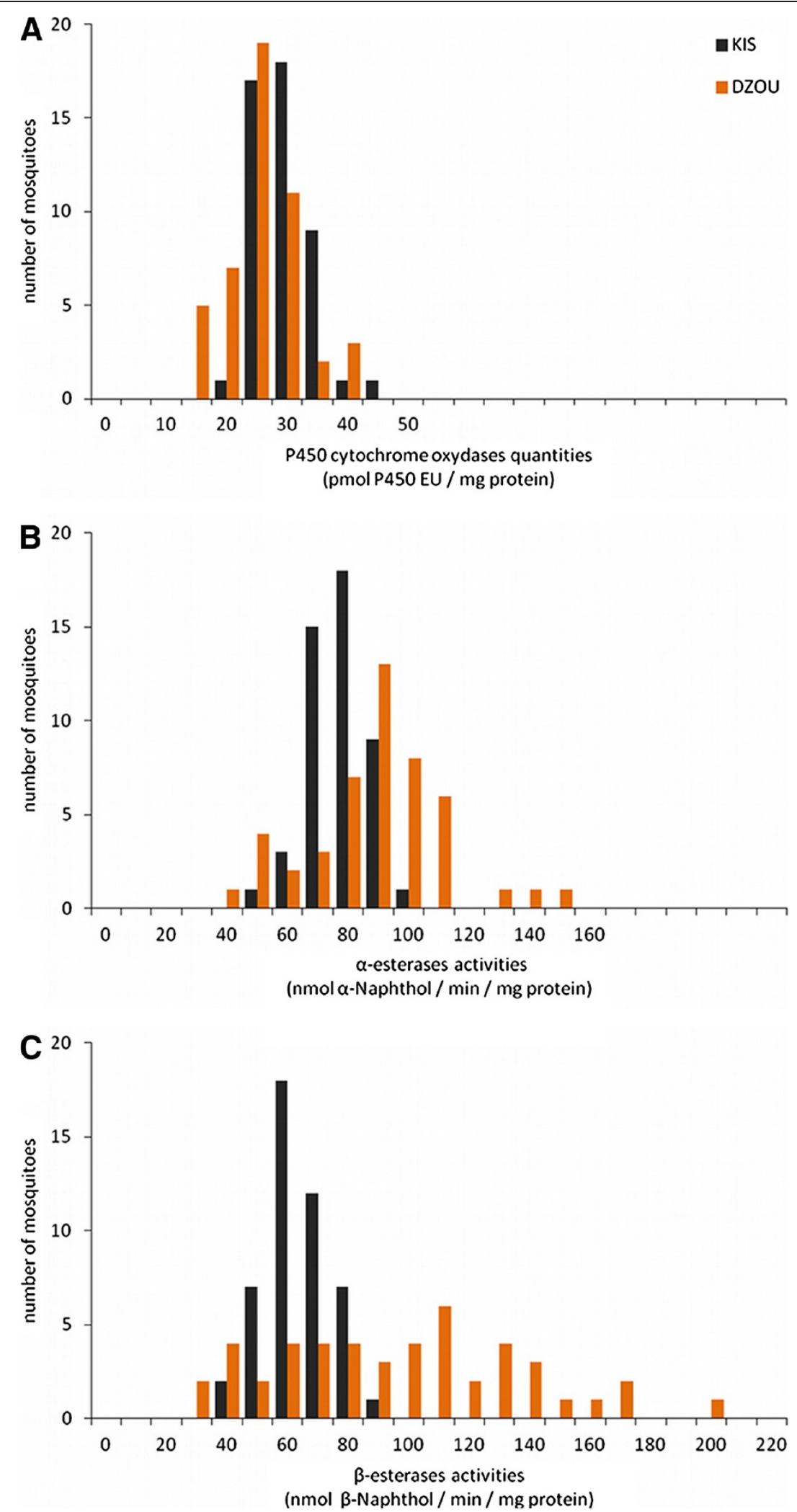

Figure 4 Comparison of detoxification enzyme quantities or activities in single mosquitoes of KIS and DZOU. The amount of cytochrome P450 oxidase (A) (MFO) is expressed in pmol of P450 Equivalent Unit per mg of protein for each mosquito. Activities of a (B) and $\beta$-esterases (C) (COE) are expressed as nmol of product formed (a or $\beta$-naphthol) per minute and per mg of protein. 
Finally, while temephos treatments have certainly favored overexpressed COE selection in the DZOU colony, they might also explain the lower MFO expression in this strain compared to KIS. Indeed, some OP, such as temephos, are bio-activated in their oxon form (the toxic form) by some oxidases, and it has been shown in $C x . p$. quinquefasciatus that MFO were counter-selected in an environment under temephos pressure [73].

\section{Low resistance in disease vectors: an opportunity for Mayotte}

In light of these results, the resistance status of vectors in Mayotte offers an unusual situation in the world of vector control. With the exception of temephos and deltamethrin resistances observed in $C x$. p. quinquefasciatus and of the low temephos resistance in An. gambiae, the four main mosquito vector species were indeed susceptible to the majority of new tested insecticides (Bti, spinosad and two IGRs). Due to very different modes of action, resistance mechanisms to OPs and CM identified in An. gambiae and Cx. p. quinquefasciatus, including COEs, should not confer cross-resistance to these new insecticides (except, maybe, for juvenile hormone analogues, see above). Moreover, temephos has been recently abandoned from the arsenal of authorized insecticides for vector control in France due to European rules [19], and no other insecticides targeting AChE1 is presently authorized. As this resistance is costly in terms of fitness (e.g. [74,75]), they should thus disappear, and should not impact the future vector control efforts.

However, in order to preserve this positive situation, the usual vector control practices should be avoided. In particular, it is important to not use exclusively a single insecticide to control mosquitoes. Bti is currently the only larvicide used for vector control in Mayotte, thanks to its many advantages: this insecticide is highly specific, with little effect on non-target organisms [76], and it is a mixture of several synergistic toxins [77], thus limiting the risk of resistance development. Unfortunately, resistance has been described in a field population of $C x . p$. pipiens from the United States [78] and resistance to separate Bti toxins in the laboratory were selected in Ae. aegypti [79] or Cx. p. quinquefasciatus [80]. Similarly, only deltamethrin is currently used for adulticides (IRS and LLINs). Its efficacy is preserved so far by the susceptibility of $A n$. gambiae. However, this absence of resistance to PYRs should be carefully monitored, as it could rapidly spread through natural selection, following its appearance by mutation or importation [81]. Finally, even if other tested insecticides (spinosad and IGRs) are used less in vector control, examples of resistance to these compounds already exist in mosquitoes [78,82-84]. The exclusive use of any of those insecticides would therefore lead to the rapid emergence and selection of resistance in mosquitoes from Mayotte.

To prevent the development of resistance in these disease vectors, various resistance management strategies can be used. One of the most efficient strategies is to alternatively use insecticides with different modes of action and for which no cross-resistance occur in target populations [26,27]. Such strategies require a large enough panel of molecules. This may be a problem since in Mayotte, as mentioned before, Bti is the only larvicide currently allowed for use in natural breeding sites with non-target fauna associated, and deltamethrin the only adulticide authorized. Moreover, alternatives would be necessary in case of emergence of resistance. Therefore, a change in the national, but also European, policies regarding pesticides agreement would be much welcome. Some molecules could be re-authorized to be used only in case of public-health threat for example. This may be the case for temephos, which is a handy, low-cost and relatively safe molecule [85]. Although low resistance to this insecticide was observed in Mayotte (Anopheles and Culex), the operational doses could remain mostly effective against these vectors [86]. This molecule could thus be used as a back-up in case of emergency. Again, it is important to stress that such back-up would not mean using a single molecule in less pressing periods, in which case emergencies would become the rule.

More generally, the absence of strong resistance in most vectors allows the local vector control programme to develop a preemptive and reasoned insecticide use strategy in order to prevent the risk of development of resistance. This is very positive as such strategies are most often only considered in dire circumstances, i.e. when resistance is installed and when they are thus the least effective. However, the fight against mosquito disease vectors in Mayotte should not be exclusively based on insecticides, but should rather follow an Integrated Vector Management strategy (IVM [87]). This strategy recommends the combination of several tools to manage vector populations: physical destruction of breeding sites, social mobilization of communities, entomological monitoring and rational use of insecticides by all those implementing any action [26,87]. A recent study compared 61 vector control interventions against dengue vectors and showed that interventions based on IVM were more effective than interventions based only on environmental management, biological control or chemical control alone [88]. IVM has already shown good results against Ae. aegypti in Singapore and Vietnam $[89,90]$. This strategy requires the collaboration of several health sectors (vector control services, epidemiologists, hospitals), but also of other sectors not directly related to health (local administration, urbanization development, immigration surveys, waste management, etc.). For example, most of the breeding sites of $C x . p$. quinquefasciatus in 
Mayotte are open sewers and latrines. Improving wastewater management and personal sanitation could greatly reduce the number of available breeding sites for this species. Similarly, the forthcoming closing of the garbage dump of Dzoumogné would limit the number of breeding sites for An. gambiae in this area.

\section{Conclusion}

Mayotte is an ideal territory to implement an IVM approach and to carefully anticipate vector control management. Indeed, the economic development of the island is now fast and many public works are ongoing. It would be relatively easy to integrate the concept of vector management in the land and city planning policies. Moreover, social mobilization is already used by the local vector control services and is continuously improved. Finally, the low levels of insecticide resistance observed in the main mosquito vectors of the island allow usage of most of the larvicide and adulticide tested here. Thus, only anticipated resistance management strategies and regular entomological surveys remain to be implemented. This unusual situation allows being relatively optimistic about the future of vector control in Mayotte.

\section{Endnote}

${ }^{a} \mathrm{NB}$ : Mayotte has recently become a French overseas administrative department and has to comply with Biocide Directive 98/8/EC.

\section{Additional files}

Additional file 1: Effects of larvicides on mosquito vectors from

Mayotte. Resistance levels of DZOU, TZ1, PT and KWI colonies to temephos, Bti, spinosad, diflubenzuron, pyriproxyfen and methopren are compared to resistance levels of the reference strains KIS and AcerKIS,

$S L A B, B O R A$ and PLP, respectively. For An. gambiae, additional tests with chlorpyrifos, malathion and propoxur are presented. $\mathrm{N}$ is the total

number of tested larvae. The 50 and $95 \%$ lethal concentrations ( $L C_{50}$ and $\mathrm{LC}_{95}$ ) and the 50 and $95 \%$ emergence inhibition concentrations (EIC $\mathrm{C}_{50}$ and $\mathrm{ElC}_{95}$ ) are expressed in $\mathrm{mg} / \mathrm{l}$, with their associated confidence intervals at 95\% ( $\left.\mathrm{Cl}_{95}\right)$. Finally, the corresponding resistant ratios (RR), i.e. the ratios of $\mathrm{LC}$ or $\mathrm{EIC}$ of the tested colony over the susceptible reference strain, are also indicated and presented in bold when significantly higher than 1 (i.e. when $\mathrm{Cl}_{95}$ does not include 1).

Additional file 2: Effect of deltamethrin on adult vector mosquitoes from Mayotte. Short-term knockdown effect and mortality at 24 hours induced by deltamethrin on DZOU, TZ1, PT, KWI colonies and KIS, SLAB, BORA and PLP reference strains are presented. $\mathrm{N}$ is the total number of tested adult females. The 50 and $95 \%$ knockdown times (KDT 50 and $\mathrm{KDT}_{95}$ ) are expressed in minutes, with their associated confidence intervals at 95\% $\left(\mathrm{Cl}_{95}\right)$. Finally, the corresponding resistant ratios (RR), i.e. the ratios of KDT of the tested colony over the susceptible reference strain, are also indicated and presented in bold when significantly higher than 1 (i.e. when $\mathrm{Cl}_{95}$ does not include 1).

Additional file 3: Effects of OP and CM larvicides on Anopheles gambiae from Mayotte. Resistance levels of the introgressed DZKIS strain are compared to resistance levels of the reference strains KIS and AcerkIS for three OP (temephos ${ }^{\mathrm{a}}$, chlorpyrifos, malathion) and one CM (propoxur) larvicides. $\mathrm{N}$ is the total number of tested larvae. The 50 and 95\% lethal concentrations $\left(L C_{50}\right.$ and $\left.L C_{95}\right)$ are expressed in $\mathrm{mg} / \mathrm{l}$, with their associated confidence intervals at $95 \%\left(\mathrm{Cl}_{95}\right)$. Finally, the corresponding resistant ratios (RR), i.e. the ratios of LC of the tested colony over the susceptible reference strain, are also indicated and presented in bold when significantly higher than 1 (i.e. when $\mathrm{Cl}_{95}$ does not include 1).

\section{Abbreviations}

OC: Organochlorines; OP: Organophosphates; CM: Carbamat; PYR: Pyrethroids; BacT: Bacterial toxins; Bti: Bacillus thuringiensis var israelensis; IGR: Insect growth regulator; LC: Lethal concentration; El: Emergence inhibition; ElC: Emergence inhibition concentration; KD: Knockdown; KDT: Knockdown times; RR: Resistance ratio; GLM: Generalized linear model; MFO: Mixed function oxidases; COE: Carboxyl-esterases;

AChE1: Acetylcholinesterase-1; IRS: Indoor residual spraying; LLIN: Long

lasting insecticide-treated net; IVM: Integrated vector management.

\section{Competing interests}

The authors declare that they have no competing interest.

\section{Authors' contributions}

Conceived and designed the experiments: NP, FD, BZ, FC. Performed the experiments: NP, FD, VB, CT. Analyzed the data: NP, PM, PL, FC. Contributed to reagents, materials and analysis tools: BZ, JT, FC. Wrote the manuscript: $N P, P L, F C$. All authors read and approved the final version of the manuscript.

\section{Acknowledgements}

We are very grateful to Nicole Pasteur and Mylène Weill for their most valuable comments, discussions and help all along the manuscript preparation, and Ohri Yamada for his support in the course of this study. We also thank the "Agence régionale de santé" (ARS) of Mayotte and "Entente Interdépartementale pour la Démoustication en Méditerranée" (EID) for technical and human resources made available. We finally thank the two anonymous reviewers for their very helpful and detailed comments that substantially improved the manuscript.

\section{Financial support}

This study was financed by the "Agence nationale de sécurité sanitaire de l'alimentation, de l'environnement et du travail" (ANSES).

\section{Author details}

${ }^{1}$ Institut de Recherche pour le Développement, Unité Mixte de Recherche MIVEGEC (IRD 224-CNRS 5290-UM1-UM2), 911, avenue Agropolis, BP 64501 34394 Montpellier cedex 5, France. ${ }^{2}$ Agence de Santé Océan Indien (ARS OI), St Denis, La Réunion Island, France. ${ }^{3}$ Institut des Sciences de l'Evolution de Montpellier (UMR 5554, CNRS-UM2-IRD), Université Montpellier 2, Montpellier, France. ${ }^{4}$ DASS Nouvelle Calédonie, Santé Environnementale, Nouméa, Nouvelle Calédonie.

Received: 25 February 2014 Accepted: 19 June 2014

Published: 1 July 2014

\section{References}

1. Grjebine A: Rapport sommaire sur la première étude des moustiques vecteurs de la filariose des iles Pamandzi et Mayotte. Paris: ORSTOM; 1956.

2. Brunhes J, Dandoy G: Géographie de la filariose de bancroft dans les iles d'Anjouan et de Mayotte (archipel des Comores). Cahier ORSTOM 1978, 15:3-15.

3. Blanchy S, Galtier J: La filariose de Bancroft a Mayotte. Etat actuel de l'endémie filarienne et programme de lutte. Cahier ORSTOM 1982, 20:153-159.

4. Julvez J, Mouchet J: Epidémiologie Historique de la filariose de bancroft dans les îles du sud-ouest de l'océan indien. Bull Soc Pathol Exot 1994, 87:194-201.

5. Galtier J, Blanchy S: Le paludisme à Mayotte et son évolution de 1976 à 1981. Cahier ORSTOM 1982, 20:145-151.

6. Julvez J, Galtier J, Ali Halidi M, Henry M, Mouchet J: Epidémiologie du paludisme et lutte antipaludique à Mayotte (archipel des Comores, Océan Indien). Evolution de la situation de 1976 à 1986. Perspectives. Bull Soc Pathol Exot 1987, 80:505-519.

7. InVS: Surveillance du paludisme à Mayotte: bilan 2012. Point Épidémiologique 2013, 17:1-2. 
8. CNEV: Circulation de Wuchereria bancrofti à Mayotte? www.cnev.fr.

9. Julvez J, Ragavoodoo C, Gopaul AR, Mouchet J: Maladies humaines transmises par les culicides dans les iles du sud-ouest de l'Ocean Indien. Bull Soc Pathol Exot 1998, 91:99-103.

10. Sissoko D, Malvy D, Giry C, Delmas G, Paquet C, Gabrie P, Pettinelli F, Sanquer MA, Pierre V: Outbreak of Chikungunya fever in Mayotte, Comoros archipelago, 2005-2006. Trans R Soc Trop Med Hyg 2008, 102:780-786.

11. Vazeille M, Moutailler S, Coudrier D, Rousseaux C, Khun H, Huerre M, Thiria J, Dehecq JS, Fontenille D, Schuffenecker I, Despres P, Failloux A-B: Two Chikungunya isolates from the outbreak of La Reunion (Indian Ocean) exhibit different patterns of infection in the mosquito Aedes albopictus. PLOS ONE 2007, 2:e1168.

12. Girod R: First record of Aedes albopictus in Mayotte Island. Comoros archipelago Parasite 2004, 11:74.

13. Bagny L, Arnoux S, Delatte H, Lajoie G, Fontenille D: Spread of invasive Aedes albopictus and decline of resident Aedes aegypti in urban areas of Mayotte 2007-2010. Biol Invasions 2012, 14:1623-1633.

14. InVS: Situation de la dengue et du chikungunya à Mayotte. Point Épidémiologique 2012, 37:1-2.

15. Sissoko D, Giry C, Gabrie P, Tarantola A, Pettinelli F, Collet L, D'Ortenzio E, Renault P, Pierre V: Rift Valley fever, Mayotte, 2007-2008. Emerg Infect Dis 2009, 15:568-570.

16. Robert V, Lagneau C: Mission de conseil et d'appui à la mise en place de la lutte intégrée contre les vecteurs à Mayotte. IRD, EID Méditerranée: Montpellier, France; 2009

17. Subra R, Hébrard G, Rabenirainy L: Essai de lutte contre Anopheles gambiae s.l. et Culex pipiens fatigans Wiedemann, 1828, par les larvicides dans une zone d'endémie filarienne, (Mayotte, Archipel des Comores). Cahier ORSTOM 1973, 11:225-231.

18. Subra R: Biology and control of Culex pipiens quinquefasciatus Say, 1823 (Diptera, Culicidae) whit special reference to Africa. Insect Sci Applic 1981, 1:319-338.

19. European Parliament: Directive $98 / 8 /$ CE du parlement européen et du conseil du 16 février 1998 concernant la mise sur le marché des produits biocides. J Officiel Communautés Européennes 1998, L123/1.

20. Bagny L, Delatte H, Elissa N, Quilici S, Fontenille D: Aedes (Diptera: Culicidae) vectors of arboviruses in Mayotte (Indian Ocean): distribution area and larval habitats. J Med Entomol 2009, 46:198-207.

21. Bonizzoni M, Gasperi G, Chen X, James AA: The invasive mosquito species Aedes albopictus: current knowledge and future perspectives. Trends Parasitol 2013, 29:460-468.

22. Hollingworth RM, Dong K: The Biochemical and Molecular Genetic Basis of Resistance to Pesticides in Arthropods. In Global Pesticide Resistance in Arthropods. Edited by Whalon ME, Mota-Sanchez D, Hollingworth RM. Cambridge, United Kingdom: CABI; 2008:40-89.

23. Pocquet N, Milesi P, Makoundou P, Unal S, Zumbo B, Atyame C, Darriet F, Dehecq J-S, Thiria J, Bheecarry A, Weill M, Chandre F, Labbé P: Multiple insecticide resistances in the disease vector Culex $p$. quinquefasciatus from Western Indian Ocean. PLoS One 2013, 8:e77855.

24. Ranson H, N'Guessan R, Lines J, Moiroux N, Nkuni Z, Corbel V: Pyrethroid resistance in African anopheline mosquitoes: what are the implications for malaria control? Trends Parasitol 2011, 27:91-98.

25. Vontas J, Kioulos E, Pavlidi N, Morou E, della Torre A, Ranson H: Insecticide resistance in the major dengue vectors Aedes albopictus and Aedes aegypti. Pestic Biochem Physiol 2012, 104:126-131.

26. Labbé P, Alout H, Djogbénou L, Pasteur N, Weill M: 14 - Evolution of Resistance to Insecticide in Disease Vectors. In Genetics and Evolution of Infectious Disease. London: Elsevier; 2011:363-409.

27. Nauen $R$ : Insecticide resistance in disease vectors of public health importance. Pest Manag Sci 2007, 63:628-633.

28. Whalon ME, Mota-sanchez D, Hollingworth RM: Analysis of Global Pesticide Resistance in Arthropods. In Global Pesticide Resistance in Arthropods. Edited by Whalon ME, Mota-Sanchez D, Hollingworth RM. Cambridge, United Kingdom: CABl; 2008:5-31.

29. Chandre F, Darriet F, Manga L, Akogbeto M, Faye O, Mouchet J, Guillet P: Status of pyrethroid resistance in Anopheles gambiae sensu lato. Bull World Health Organ 1999, 77:230-234.

30. Georghiou GP, Metcalf RL, Gidden FE: Carbamate-resistance in mosquitos. Selection of Culex pipiens fatigans Wiedemann ( $=C$. quinquefasciatus Say) for resistance to Baygon. Bull World Health Organ 1966, 35:691-708.
31. Brengues C, Hawkes NJ, Chandre F, McCarroll L, Duchon S, Guillet P, Manguin S, Morgan JC, Hemingway J: Pyrethroid and DDT cross-resistance in Aedes aegypti is correlated with novel mutations in the voltage-gated sodium channel gene. Med Vet Entomol 2003, 17:87-94.

32. Tantely ML, Tortosa P, Alout H, Berticat C, Berthomieu A, Rutee A, Deheca JS, Makoundou P, Labbé P, Pasteur N, Weill M: Insecticide resistance in Culex pipiens quinquefasciatus and Aedes albopictus mosquitoes from La Reunion Island. Insect Biochem Mol Biol 2010, 40:317-324.

33. Djogbénou L, Weill M, Hougard JM, Raymond M, Akogbeto M, Chandre F: Characterization of insensitive acetylcholinesterase $\left(a c e-1^{R}\right)$ in Anopheles gambiae (Diptera: Culicidae): resistance levels and dominance. J Med Entomol 2007, 44:805-810.

34. Weill M, Lutfalla G, Mogensen K, Chandre F, Berthomieu A, Berticat C, Pasteur N, Philips A, Fort P, Raymond M: Comparative genomics: insecticide resistance in mosquito vectors. Nature 2003, 423:136-137.

35. WHO: Guidelines for Laboratory and Field Testing of Mosquito Larvicides. Geneva, Switzerland: World Health Organization; 2005.

36. WHO: Guidelines for Testing Mosquito Adulticides for Indoor Residual Spraying and Treatment of Mosquito Nets. Geneva, Switzerland: World Health Organization; 2006

37. WHO: Report of the WHO Informal Consultation Tests Procedures for Insecticide Resistance Monitoring in Malaria Vectors, Bio-efficacy and Persistence of Insecticides on Treated Surfaces. Geneva: World Health Organization; 1998.

38. R Core Team: R: a language and environment for statistical computing. 2013.

39. Milesi P, Pocquet N, Labbé P: BioRssay: a R script for bioassay analyses. http://www.isem.univ-montp2.fr/recherche/equipes/genomique-deladaptation/personnel/labbe-pierrick/.

40. Johnson RM, Dahlgren $L$, Siegfried $B D$, Ellis MD: Acaricide, fungicide and drug interactions in honey bees (Apis mellifera). PLOS ONE 2013, 8:e54092.

41. Finney DJ: Probit Analysis. Cambridge: Cambridge University Press; 1971.

42. Abbott W: A method of computing the effectiveness of an insecticide. J Econ Entomol 1925, 18:265-267.

43. Nielsen-Leroux C, Pasquier F, Charles JF, Sinegre G, Gaven B, Pasteur N: Resistance to Bacillus sphaericus involves different mechanisms in Culex pipiens (Diptera:Culicidae) larvae. J Med Entomol 1997, 34:321-327.

44. Bradford MM: Rapid and sensitive method for quantitation of microgram quantities of protein utilizing principle of protein-dye binding. Anal Biochem 1976, 72:248-254.

45. Brogdon WG, MCAllister JC, Vulule J: Heme peroxidase activity measured in single mosquitoes identifies individuals expressing an elevated oxidase for insecticide resistance. J Am Mosq Control Assoc 1997, 13:233-237.

46. Hemingway J: Techniques to Detect Insecticide Resistance Mechanisms (Field and Laboratory Manual). Geneva: World Health Organization; 1998.

47. StatSoft: STATISTICA (Logiciel d'Analyse des Données), Version 10. 2011.

48. Rogers SO, Bendich AJ: Extraction of DNA from Plant Tissues. Boston: Kluwer Academic Publisher; 1988.

49. Weill M, Malcolm C, Chandre F, Mogensen K, Berthomieu A, Marquine M, Raymond $\mathrm{M}$ : The unique mutation in ace-1 giving high insecticide resistance is easily detectable in mosquito vectors. Insect Mol Biol 2004, 13:1-7.

50. Martinez-Torres D, Chandre F, Williamson MS, Darriet F, Berge JB, Devonshire AL, Guillet P, Pasteur N, Pauron D: Molecular characterization of pyrethroid knockdown resistance $(k d r)$ in the major malaria vector Anopheles gambiae s.s. Insect Mol Biol 1998, 7:179-184.

51. Ranson H, Jensen B, Vulule JM, Wang X, Hemingway J, Collins FH: Identification of a point mutation in the voltage-gated sodium channel gene of Kenyan Anopheles gambiae associated with resistance to DDT and pyrethroids. Insect Mol Biol 2000, 9:491-497.

52. Martinez-Torres D, Chevillon C, Brun-Barale A, Berge JB, Pasteur N, Pauron D: Voltage-dependent $\mathrm{Na}+$ channels in pyrethroid-resistant Culex pipiens $\mathrm{L}$ mosquitoes. Pesticide Science 1999, 55:1012-1020.

53. Corbet PS, Smith SM: Diel periodicities of landing of nulliparous and parous Aedes aegypti (L.) at Dar es Salaam, Tanzania (Diptera, Culicidae). Bull Entomol Res 1974, 64:111-121.

54. Delatte H, Desvars A, Bouétard A, Bord S, Gimonneau G, Vourc'h G, Fontenille D: Blood-feeding behavior of Aedes albopictus, a vector of Chikungunya on La Réunion. Vector Borne and Zoonotic Diseases 2010, 10:249-258 
55. Perich MJ, Davila G, Turner A, Garcia A, Nelson M: Behavior of resting Aedes aegypti (Culicidae: Diptera) and its relation to ultra-low volume adulticide efficacy in Panama City, Panama. J Med Entomol 2000, 37:541-546.

56. Pates $\mathrm{H}$, Curtis C: Mosquito behavior and vector control. Annu Rev Entomol 2005, 50:53-70.

57. Marcombe S, Mathieu RB, Pocquet N, Riaz MA, Poupardin R, Selior S, Darriet F, Reynaud S, Yebakima A, Corbel V, David JP, Chandre F: Insecticide resistance in the dengue vector Aedes aegypti from Martinique: distribution, mechanisms and relations with environmental factors. PLOS ONE 2012, 7:e30989.

58. Weill M, Berthomieu A, Berticat C, Lutfalla G, Negre V, Pasteur N, Philips A, Leonetti JP, Fort P, Raymond M: Insecticide resistance: a silent base prediction. Curr Biol 2004, 14:R552-R553.

59. Mohandass SM, Arthur FH, Zhu KY, Throne JE: Hydroprene: mode of action, current status in stored-product pest management, insect resistance, and future prospects. Crop Protection 2006, 25:902-909.

60. Quatresous I, Jeannel D, Sissoko D: Épidémiologie du Paludisme à Mayotte: état des lieux 2003-2004 et Propositions. Institut de veille sanitaire: SaintMaurice; 2005

61. Diabate A, Baldet T, Chandre F, Akogbeto M, Guiguemde TR, Darriet F, Brengues C, Guillet P, Hemingway J, Small GJ, Hougard JM: The role of agricultural use of insecticides in resistance to pyrethroids in Anopheles gambiae s.I. in Burkina Faso. Am J Trop Med Hyg 2002, 67:617-622.

62. Yadouleton A, Martin T, Padonou G, Chandre F, Asidi A, Djogbenou L, Dabire R, Aikpon R, Boko M, Glitho I, Akogbeto M: Cotton pest management practices and the selection of pyrethroid resistance in Anopheles gambiae population in northern Benin. Parasit Vectors 2011, 4:60.

63. Pinto J, Lynd A, Vicente JL, Santolamazza F, Randle NP, Gentile G, Moreno M, Simard F, Charlwood JD, Do Rosario VE, Caccone A, della Torre A, Donnelly MJ: Multiple origins of knockdown resistance mutations in the afrotropical mosquito vector Anopheles gambiae. PLOS ONE 2007, 2:e1243.

64. Oakeshott JG, Devonshire AL, Claudianos C, Sutherland TD, Horne I, Campbell PM, Ollis DL, Russell RJ: Comparing the organophosphorus and carbamate insecticide resistance mutations in cholin- and carboxylesterases. Chemico-Biological Interactions 2005, 157-158:269-275.

65. Pasteur N, Raymond M: Insecticide resistance genes in mosquitoes: their mutations, migration, and selection in field populations. Journal of Heredity 1996, 87:444-449.

66. Liu Y, Zhang H, Qiao C, Lu X, Cui F: Correlation between carboxylesterase alleles and insecticide resistance in Culex pipiens complex from China. Parasit Vectors 2011, 4:236.

67. Wirth M, Georghiou G: Selection and characterization of temephos resistance in a population of Aedes aegypti from Tortola, British Virgin Islands. J Am Mosa Control Assoc 1999, 15:315-320.

68. Bisset JA, Marín R, Rodríguez MM, Severson DW, Ricardo Y, French L, Díaz M, Pérez O: Insecticide resistance in two Aedes aegypti (Diptera: Culicidae) strains from Costa Rica. J Med Entomol 2013, 50:352-361.

69. Namountougou M, Simard F, Baldet T, Diabate A, Ouedraogo JB, Martin T, Dabire RK: Multiple insecticide resistance in Anopheles gambiae s.l. populations from Burkina Faso, West Africa. PLOS ONE 2012, 7:e48412.

70. Koffi A, Alou L, Adja M, Koné M, Chandre F, N'Guessan R: Update on resistance status of Anopheles gambiae s.s. to conventional insecticides at a previous WHOPES field site, "Yaokoffikro", 6 years after the political crisis in Côte d'Ivoire. Parasit Vectors 2012, 5:68.

71. Tene Fossog B, Kopya E, Ndo C, Menze-Djantio B, Costantini C, Njiokou F, Awono-Ambene P, Antonio-Nkondjio C: Water quality and Anopheles gambiae larval tolerance to pyrethroids in the cities of Douala and Yaounde (Cameroon). J Trop Med 2012, 2012:429817.

72. Nkya TE, Akhouayri I, Kisinza W, David JP: Impact of environment on mosquito response to pyrethroid insecticides: facts, evidences and prospects. Insect Biochem Mol Biol 2013, 43:407-416.

73. Hardstone MC, Lazzaro BP, Scott JG: The effect of three environmental conditions on the fitness of cytochrome P450 monooxygenase-mediated permethrin resistance in Culex pipiens quinquefasciatus. BMC Evolutionary Biology 2009, 9:42

74. Berticat C, Boquien G, Raymond M, Chevillon C: Insecticide resistance genes induce a mating competition cost in Culex pipiens mosquitoes. Genet Res 2002, 79:41-47.
75. Duron O, Labbé P, Berticat C, Rousset F, Guillot S, Raymond M, Weill M: High Wolbachia density correlates with cost of infection for insecticide resistant Culex pipiens mosquitoes. Evolution 2006, 60:303-314.

76. Lacey LA: Bacillus thuringiensis serovariety israelensis and Bacillus sphaericus for mosquito control. J Am Mosq Control Assoc 2007, 23:133-163.

77. Bravo A, Gill SS, Soberon M: Mode of action of Bacillus thuringiensis Cry and Cyt toxins and their potential for insect control. Toxicon 2007, 49:423-435

78. Paul A, Harrington LC, Zhang L, Scott JG: Insecticide resistance in Culex pipiens from New York. J Am Mosq Control Assoc 2005, 21:305-309.

79. Paris M, Tetreau G, Laurent F, Lelu M, Despres L, David J-P: Persistence of Bacillus thuringiensis israelensis (Bti) in the environment induces resistance to multiple Bti toxins in mosquitoes. Pest Manag Sci 2011, 67:122-128.

80. Wirth MC, Walton WE, Federici BA: Inheritance patterns, dominance, stability, and allelism of insecticide resistance and cross-resistance in two colonies of Culex quinquefasciatus (Diptera: Culicidae) selected with Cry toxins from Bacillus thuringiensis subsp. israelensis. J Med Entomol 2010, 47:814-822.

81. Stump AD, Atieli FK, Vulule JM, Besansky NJ: Dynamics of the pyrethroid knockdown resistance allele in western Kenyan populations of Anopheles gambiae in response to insecticide-treated bed net trials. Am J Trop Med Hyg 2004, 70:591-596.

82. Cornel A, Stanich M, McAbee R, Mulligan F: High level methoprene resistance in the mosquito Ochlerotatus nigromaculis (Ludlow) in central California. Pest Manag Sci 2002, 58:791-798.

83. Kasai S, Shono T, Komagata O, Tsuda Y, Kobayashi M, Motoki M, Kashima I, Tanikawa T, Yoshida M, Tanaka I, Shinjo G, Hashimoto T, Ishikawa T, Takahashi T, Higa Y, Tomita T: Insecticide resistance in potential vector mosquitoes for West Nile virus in Japan. J Med Entomol 2007, 44:822-829.

84. Su T, Cheng M-L: Resistance development in Culex quinquefasciatus to spinosad: a preliminary report. J Am Mosq Control Assoc 2012, 28:263-267.

85. Tomlin CDS: The pesticide Manual: a World Compendium. Fifteenthth edition. BCPC: Alton, England; 2009.

86. WHO: Pesticides and their Application for the Control of Vectors and Pests of Public Health Importance. Sixthth edition. Geneva, Switzerland: World Health Organization; 2006

87. Berg H, Mutero CM, Ichimori K: Guidance on Policy-Making for Integrated Vector Management. Geneva: World Health Organisation; 2012.

88. Erlanger T, Keiser J, Utzinger J: Effect of dengue vector control interventions on entomological parameters in developing countries: a systematic review and meta-analysis. Med Vet Entomol 2008, 22:203-221.

89. Ooi E-E, Goh K-T, Gubler D: Dengue prevention and 35 years of vector control in Singapore. Emerging infectious diseases 2006, 12:887-893.

90. Kay B, Vu S: New strategy against Aedes aegypti in Vietnam. Lancet 2005, 365:613-617.

\section{doi:10.1186/1756-3305-7-299}

Cite this article as: Pocquet et al: Insecticide resistance in disease vectors from Mayotte: an opportunity for integrated vector management. Parasites \& Vectors 2014 7:299.

\section{Submit your next manuscript to BioMed Central and take full advantage of:}

- Convenient online submission

- Thorough peer review

- No space constraints or color figure charges

- Immediate publication on acceptance

- Inclusion in PubMed, CAS, Scopus and Google Scholar

- Research which is freely available for redistribution 